in a discussion of the prognosis of cystic fibrosis, the example quoted of athleticism in a patient with Schwachman's disease "a disease similar to CF" is misleading. In the chapter on multifactorial inheritance the concept of heritability is repeatedly invoked without any explanation of its precise meaning. On page 106, a high heritability is taken to indicate resistance of a trait to environmental manipulations; however, a trait with $100 \%$ heritability may be entirely prevented by new environments which were not operating when the heritability was estimated. On pages 172 and 173, conflicting patterns of multifactorial inheritance are presented without explanation. On the one hand, "The offspring of two very short persons should be taller than both their parents" because of "Galton's law of regression towards the mean", but on the next page, "the body build indices of the progeny ... are exactly intermediate between those of their parents" indicating "multigenic inheritance". Both statements could be true, but without additional explanation this could be puzzling.

In conclusion, this is a book to be read straight through by newcomers to genetic counselling who have some knowledge of medicine. They will find many useful insights and suggestions for further reading, but they may need guidance in places from a more experienced colleague.

N R DENNIS

\section{Genetic Engineering 2}

Edited by Robert Williamson. (Pp xii +204; figures + tables. $£ 9.80, \$ 24.00$.) London, New York: Academic Press. 1981.

Genetic Engineering 1 (reviewed in the April 1982 issue) set a high standard for this series, with substantial up to date contributions from leading researchers in the field. Genetic Engineering 2 is even better.

The contributions in both books are sufficiently detailed to be useful to scientists actively involved in recombinant DNA techniques at the bench, but it would be wrong to imagine that these scientists are the only people who would benefit from reading these books. The present reviewer is one of a large and growing number of people who, although not involved at the bench, is nevertheless concerned with the application of recombinant DNA techniques in his own particular field. For these people Genetic Engineering 2 makes a better introduction than book 1 , for the former starts with an excellent 40 page paper on 'Recent Studies of Gene Evolution using Recombinant DNA' by Dr Jeffreys. This sets the scene perfectly for an 80 page account on the
'Use of Genomic Libraries for the Isolation and Study of Eukaryotic Genes' by Dahl, Flavell, and Grosveld. These two papers, together with Dr Malcolm's discussion of the use of restriction enzymes (the starting point for the DNA revolution), provide an admirable way into the field for those who have grasped the general principles but are frustrated by the lack of clear account of the practical details. The book finishes with a paper on 'Gene Cloning in Yeast' by Dr Beggs.

This book is strongly recommended to anyone with a simple basic knowledge of molecular biology who has an interest in genetic engineering and its application. I can't wait for book 3 !

\section{E Pembrey}

\section{DNA Repair and Mutagenesis in Eukaryotes}

Basic Life Sciences vol 15. Edited by W M Generoso, $M$ D Shelby, and F J de Serres. (Pp xii +458; figures + -tables. \$49.50). New York: Plenum Press. 1980.

This volume consists of the proceedings of a symposium on 'DNA Repair and Mutagenesis in Eukaryotes', which took place in Atlanta in June 1979 under the sponsorship of the National Institute of Environmental Health Sciences. It contains 31 contributions, divided into six sections. The first of these sections sets the stage with three reviews: one by Kimball on the relationship between repair processes and mutation induction in bacteria; one by Straus et al on the modification, by cellular systems, of the response to chemical mutagens (this mainly reports recent work from the authors' laboratory); and, finally, one by Setlow on DNA repair pathways, with emphasis on excision repair. The other five sections deal, in order, with data on lower eukaryotes, Drosophila, mammalian somatic cells, mouse germ cells, and human health hazard assessment. Each one of these sections ends with a summary chapter, which guides the reader through the material of the book.

The second section is subdivided into two parts. The first consists of three chapters by Schroeder and Olson, Fraser et al, and de Serres on the characteristics of mutants of Neurospora crassa sensitive to mutagens, and the effects of such inherited mutations on mutation induction. The second has five contributions (including the summary chapter by Brockman) on Saccharomyces cerevisiae. Here papers by Lemontt, Reynolds and Friedberg, Prakash and Prakash, and von Borstel and Hastings on DNA repair and mutagenesis reveal differences and similarities between such processes in bacteria and yeast. 
The third section deals with the isolation and characterisation of repair deficient mutants in Drosophila (Smith et al), the effect of meiotic and repair mutants on chromosome behaviour (Baker et al), the biochemistry of some repair mutants (Boyd et al), and the induction of mutations in repair mutants (Würgler and Graf). All this is summarised and put into perspective by Green.

Section IV, presumably the most relevant to the readers of the Journal of Medical Genetics, comprises eight contributions plus a summary chapter by Wolff. The section begins with a discussion of the role of DNA lesions and their repair in the production of chromosomal aberrations (Bender), followed by one on the relationship between DNA repair, chromosomal aberrations, and the potentially lethal damage caused by $x$-rays (Fornace $e t$ al). Further discussion of DNA repair in relation to chromosome aberrations (including the production of sister chromatid exchanges) is provided by Sasaki, while McCormick and Maher report on the repair systems which modify the yield of mutations in human cells in culture. Trosko et al then describe attempts both to use resistance to diptheria toxin as a marker for mutagenesis in cultured mammalian cells and to isolate DNA repair deficient Chinese hamster cell lines. This is followed by three brief reports: one on induction of mutation by ultraviolet radiations (UVR) in a UVR sensitive variant of the L5178Y mouse lymphoma cell line (Sato), one on the DNA replication and pyrimidine dimer excision in human fibroblasts receiving single or split doses of UVR (Waters), and one on the inhibition by aphidicolin of the DNA synthesis of isolated nuclei (Bertazzoni et al).

The section on mouse germ cells contains papers on the unscheduled DNA synthesis of male (Sega) and female (Pedersen and Brandriff) germ cells. Generoso reports on the effect of repair processes, in the fertilised eggs, on the yield of dominant lethal mutations and chromosome translocations induced by exposure of male postmeiotic germ cells to chemical mutagens, and Russel contributes the summary paper. The final section comprises a chapter by German on the human chromosomal instability syndromes and a brief note by Langley on DNA repair and assessment of risks to the human population.

This volume covers a lot of ground and cannot be expected to do it systematically. However, the $\stackrel{\mathbb{D}}{\rightarrow}$ editors have paid much attention to the arrangement of its material and the summary chapters provide $\stackrel{\sim}{\stackrel{\leftrightarrow}{+}}$ continuity. These chapters, together with the general $\bar{c}$ reviews, should be very useful to the non-specialist, $\frac{\bar{\sigma}}{\bar{F}}$ while the other contributions present a good $\frac{\bar{s}}{7}$ spectrum of current trends in DNA repair and $\stackrel{\mathbb{Q}}{\Omega}$ mutagenesis in eukaryotes.

F B Giannelli

\section{Genetics: Human Aspects}

By A P Mange and E J Mange. (Pp x + 675; figures + tables.) Philadelphia: Saunders College, Holt, $\vec{\bullet}$ Rinehart and Winston. 1980.

Contrary to the impression given by the title, the authors of this book aim to provide a comprehensive textbook of human genetics. It is well bound and printed and is written in a clear attractive style, $\vec{c}$ being punctuated by numerous line drawings of high quality. The book is open to three criticisms. The authors expect very little of the reader's previous knowledge, even to the extent of providing appendices on basic algebra and organic chemistry, making the book much longer and hence more expensive. Secondly, the lack of medical background in the authors is evident in those sections devoted to clinical subjects. There is less depth and a considerable number of errors or omissions. It is suggested, for instance, that congenital adrenal hyperplasia results from defects in the biosynthesis of testosterone by the testes, the adrenal glands, or both, and that males with adrenogenital syndrome usually have ambiguous genitalia.

The third and most important criticism is that the book falls between stools in the British market. As a reference textbook it cannot compete with Vogel and Motulsky and yet is too long and expensive to recommend to students, particularly in medicine. It is of potential value to the medical practitioner who wishes to expand a knowledge of basic human genetics. The clear illustrations and problem lists with each chapter may prove useful to the geneticist $\mathcal{N}$ responsible for student lectures, and on this basis $N$ it is worth adding to the collection of genetic N departments. 